\title{
A eleição parlamentar no Mercosul
}

\author{
Parliamentary election in Mercosur
}

KARINA PASQUARIELLO MARIANO*

Rev. Bras. Polít. Int. 54 (2): 138-157 [2011]

\section{Introdução}

Em 2003, quando os presidentes dos países do Mercado Comum do Sul (Mercosul) promoveram um novo impulso na integração regional, reforçaram a ideia de que o aprofundamento da agenda integracionista passaria por um ajuste institucional e pela ampliação da temática social nas negociações. Consideraram como um passo fundamental a institucionalização de um parlamento regional que suscitou desde o início um intenso debate entre os céticos sobre a necessidade dessa instância numa União Aduaneira imperfeita, frágil e que estaria propensa a retroceder a uma zona de livre comércio e os defensores do aprofundamento do processo que entendem a integração regional não apenas como uma estratégia de política externa, mas como uma questão de identidade ou destino coletivo, e para a qual o parlamento é um instrumento central na sua consolidação e democratização.

Apesar do intenso debate gerado por essas visões, há poucos estudos sobre o impacto real da ação parlamentar no âmbito do Mercosul, ainda que esta ocorra desde o início desse processo por meio da extinta Comissão Parlamentar Conjunta do Mercosul (CPCM). Essa lacuna nas análises sobre as consequências da participação legislativa na integração torna esse debate muito mais ideológico e não contribui para o real aprimoramento das instituições regionais.

A proposta deste artigo é levantar alguns aspectos centrais sobre o papel desempenhado pelos parlamentares no âmbito da integração que permitam um novo patamar para esse debate e para a compreensão da efetiva contribuição do Parlamento do Mercosul (Parlasul) no aprofundamento e democratização do Mercosul.

Assumo nesta análise que, por princípio, o estabelecimento de um parlamento é um avanço no sentido de um aprofundamento no processo de integração porque representa a incorporação de uma agenda mais ampla, que ultrapassa os limites

\footnotetext{
* Professora do Departamento de Antropologia, Política e Filosofia da Universidade Estadual Paulista (Unesp), Coordenadora do Grupo de Estudos Interdisciplinares sobre Cultura e Desenvolvimento (GEICD) e Pesquisadora do Centro de Estudos de Cultura Contemporânea (Cedec) (karinapmariano@gmail.com).
} 
dos acordos comerciais. Contudo, não é uma variável causal, isto é, apenas sua existência não garante que isso ocorra, dependendo da capacidade dessa instância de interferir no processo decisório e se fortalecer como uma esfera de representação de interesses.

Esta análise trabalha também com dois pressupostos importantes. Em primeiro lugar, considero que não há nos governos do Mercosul (inclusive nos recentemente eleitos) disposição em retroceder do atual estágio de integração. Embora a união aduaneira esteja incompleta e haja dificuldade em consolidá-la, a vontade política manifesta tanto em discursos como em decisões tomadas reforça a ideia de avançar na consolidação de um projeto de integração para além da esfera comercial.

O segundo pressuposto é que embora defenda-se um aprofundamento da integração, a lógica institucional do Mercosul permanece estritamente intergovernamental, não havendo disposição por parte dos negociadores em dar mais autonomia para as instâncias regionais.

A supranacionalidade não garante a consolidação ou aprofundamento de um processo de integração, mas, no caso europeu, permitiu a legitimação de alguns órgãos como instâncias responsáveis por determinadas decisōes, contribuindo para o reconhecimento da importância do bloco no cotidiano das sociedades envolvidas e no continuísmo das políticas regionais apesar das mudanças de governos. No caso do Mercosul, o forte intergovernamentalismo restringe essa possibilidade, mantendo o processo preso aos interesses dos governos de ocasião e, portanto, mais suscetível às mudanças eventuais resultantes da alternância de poder.

Essa suscetibilidade é uma das razóes da instabilidade do Mercosul e da dificuldade em consolidar a união aduaneira. Interesses domésticos se sobrepõem às decisões do bloco, reforçando a adoção de medidas protecionistas, especialmente em momentos de tensão política interna. Para os defensores do aprofundamento desse processo, é preciso uma mudança estrutural porque a institucionalidade vigente tende a centralizar excessivamente as decisões e a torná-las mais demoradas. De outro lado, os partidários do intergovernamentalismo argumentam que essa saída burocratizaria o bloco, aumentando os seus custos, e seria inadequada para a atual etapa de integração.

Essa dicotomia se reproduz em outra questão: o significado de aprofundamento. Para alguns, o aprofundamento do processo se dá pela ampliação de seus integrantes, e a consolidação da união aduaneira, com o fortalecimento da lógica intergovernamental. Essa foi claramente a posição defendida pela diplomacia brasileira nos últimos anos. Outros acreditam que a integração se aprofunda conforme incorpora uma nova agenda - que vai muito além dos acordos comerciais - e reforça a importância das instituiçōes regionais, defendendo a ampliação da institucionalidade do bloco e aceitando algum grau de supranacionalidade.

A institucionalização do Parlasul resultou da pressão desse segundo grupo. Justifico essa afirmação com duas observações: em primeiro lugar, já existia uma 
instância de participação para os representantes dos Congressos nacionais dos países-membros, a CPCM; em segundo lugar, a decisão em estabelecer eleiçôes diretas para a escolha dos representantes parlamentares. O Parlasul não é apenas uma representação legislativa no bloco, mas a primeira instância que pressupóe uma interação mais direta com a sociedade e a institucionalização de regras democráticas para a escolha de seus integrantes; todos os demais participantes das negociaçóes e instituições são nomeados, inclusive os representantes da sociedade civil.

A discussão deste artigo centra-se em que medida o Parlasul representa uma modificação na lógica preponderante dos negociadores quanto ao significado do aprofundamento da integração, aceitando ou não a transferência de autoridade e autonomia para a institucionalidade regional. Analisando o comportamento dos parlamentares brasileiros tanto na CPCM como no Parlasul, procuro compreender as motivaçôes de suas ações e como elas afetam a própria evolução da integração no Cone Sul.

\section{A evolução da representação parlamentar no Mercosul}

Oliver Dabène expressa a percepção de muitos analistas sobre a participação parlamentar no Mercosul: "La ausencia de tradición parlamentaria en la región, y el descrédito profundo que golpea a las clases políticas, hacen dudar del potencial legitimador de un Parlamento (...)" (2004, 127). Apesar da percepção pessimista, encontramos novos questionamentos e comportamentos que poderão impulsionar mudanças importantes. Em primeiro lugar, houve uma alteração importante na conjuntura regional e essa é uma variável importante na determinação dos comportamentos dos atores envolvidos.

O início da cooperação no Cone Sul se deu pela aproximação entre Argentina e Brasil em 1985, quando o processo de redemocratização era o centro das atençôes dos sistemas políticos desses países, exigindo um esforço conjunto na reconstrução das instituições democráticas e na definição de um projeto de nação, num contexto econômico e social desfavorável. Os parlamentares estavam voltados prioritariamente para os assuntos internos e entenderam a cooperação entre Brasil e Argentina como uma estratégia de política externa dos Executivos.

Portanto, esse início da integração recebeu pouca atenção do Congresso brasileiro, que estava absorto com a questão da reforma constituinte, voltado quase que exclusivamente para as chamadas questôes nacionais, especialmente a reformulação das relações entre os poderes Executivo e Legislativo e a superação dos problemas econômicos. Do lado argentino havia uma situação semelhante: preocupação com a consolidação da democracia e com a estagnação econômica.

A atenção parlamentar para a integração começou de fato somente a partir do Tratado de Integração Cooperação e Desenvolvimento entre Brasil e Argentina, assinado em 29 de novembro de 1988, que estabeleceu o Programa de Integração 
e Cooperação Econômica (Pice) e instituiu a Comissão Parlamentar Conjunta de Integração (CPCI).

A criação dessa Comissão pelos órgãos do Executivo no Mercosul foi um ato de interesse pragmático das instâncias decisórias dos governos no sentido de garantir maior agilidade na implementação dos acordos estabelecidos no âmbito da integração e que necessitassem de aprovação do Legislativo, mas tomando o cuidado de não lhe atribuir a capacidade de intervir nas negociações. Não houve qualquer mobilização anterior dos parlamentares reivindicando essa participação; na verdade, os Congressos foram convocados a indicar 12 legisladores de cada país para cumprirem um mandato de dois anos nessa comissão.

No caso brasileiro, a característica da participação parlamentar no Mercosul até a constituição do Parlasul foi de distanciamento entre a integração e os interesses ou agenda do Congresso. Houve nesse período um desconhecimento constante no legislativo nacional sobre a sua própria atuação no bloco regional.

Mesmo quando a integração se ampliou incorporando Paraguai e Uruguai com o Tratado de Assunção (março de 1991), não houve uma alteração significativa na situação dos representantes parlamentares. A estrutura institucional do Mercosul naquele momento estabeleceu dois órgãos com poder decisório - o Conselho do Mercado Comum (CMC) e o Grupo Mercado Comum (GMC) -, e duas outras instâncias sem a atribuição de órgão do Mercosul e, consequentemente, também sem poder decisório - a CPCM e a Secretaria Administrativa do Mercosul.

Contudo, o Tratado de Assunção não especificou como se daria essa troca de informações e nem qual seria concretamente o seu papel (Mariano 2001; Oliveira 2003). Essas especificaçóes se definiriam no Regimento Interno da CPCM, aprovado somente em 6 de dezembro de 1991, durante a III Reunião dos Parlamentares do Mercosul, realizada em Montevidéu.

Como observa Mariana Vasquez (2001), o referido Regulamento ${ }^{1}$ estabeleceu funções que não estavam presentes no Tratado de Assunção e, acrescento, não referidas em qualquer documento anterior nesse processo de integração, como estabelecer ações para a instalação de um parlamento regional, realizar estudos sobre harmonização legislativa e a criação de normas de direito comunitário.

No entanto, a CPCM, no período de transição (março de 1991 a dezembro de 1994), não logrou desempenhar tais atribuições mais abrangentes que estabelecera para si, como tampouco realizou funções deliberativas e de formulação de propostas, o que implicaria ampliar seu papel dentro do processo decisório, ou seja, ter uma participação efetiva nas discussões e capacidade de implementação de uma agenda, e elaboração de normativas (Mariano 2001).

A CPCM herdou tacitamente as características da CPCI no que tange à sua função consultiva e também no que diz respeito ao não ingresso na estrutura organizacional do Mercosul, mantendo-se à margem do processo decisório do bloco.

1 Não consta no Regimento Interno da CPC as diretrizes e mecanismos para a internalização da normativa do Mercosul nos ordenamentos jurídicos dos Estados como argumenta Rivas (2006). 
A centralização do processo decisório do Mercosul nos representantes do Poder Executivo era uma característica já presente no período anterior e que se consolida com o Tratado de Assunção, traduzindo-se na opção pela intergovernamentalidade institucional e justificada pela necessidade de maior agilidade nas decisões para poder atingir a meta ambiciosa estabelecida pelo Protocolo de las Leñas, que priorizava as negociações comerciais da Tarifa Externa Comum e a consolidação da União Aduaneira até 31 de dezembro de 1994.

Além das dificuldades internas ao próprio processo de integração, a atuação parlamentar encontrava obstáculos também dentro dos Congressos. A seção brasileira da CPC não se constituiu como comissão parlamentar permanente nesse período; portanto, não obtinha recursos para realização de seus trabalhos.

A falta de reconhecimento como uma comissão permanente do Congresso limitou suas ações, não somente pelos aspectos orçamentários, mas devido ao fato de que "(...) suas atividades não entram na agenda oficial do Congresso" (Oliveira 2003, 159). A consequência imediata foi o esvaziamento do próprio papel da CPC como agilizadora da entrada em vigor das normas emanadas do Mercosul e como harmonizadora da legislação entre os países, já que não tinha repercussão alguma no Congresso (ibid.; Mariano 2001; Drummond 2010).

$\mathrm{O}$ fato de a CPC não fazer parte da estrutura do Mercosul e não existir como comissão parlamentar permanente em seus respectivos Congressos dificultava sobremaneira a realização de seus trabalhos. No primeiro caso, o principal obstáculo para acompanhar as negociações era porque não recebia informaçôes do GMC sobre o andamento das mesmas. Embora durante o período de transição os parlamentares acreditassem que isso acontecia porque a CPC não fazia parte da estrutura institucional do bloco, após o Protocolo de Ouro Preto, quando a Comissão passou a integrar formalmente essa estrutura, esse problema persistiu (Mariano 2001).

A implicação central dessa desinformação por parte da CPC é que as normativas produzidas pelo CMC eram decididas sem nenhuma participação parlamentar, cuja atuação restringia-se a analisar as decisões para incorporá-las nas legislaçôes nacionais, sem capacidade de alterá-las, devendo simplesmente aprovar ou rejeitar as mesmas.

Rivas (2006) aponta ${ }^{2}$ que as internalizações da normativa do Mercosul às legislações nacionais por intermédio das seções nacionais da CPC tiveram escassos resultados. Particularmente no caso do Brasil, menos de $1 \%$ das normas do Mercosul foram ditadas por processo legislativo ${ }^{3}$. O restante das normativas internalizou-se por meio de instrumentos do Executivo (Decretos, Resoluções e Portarias, entre outros).

2 Os dados analisados correspondem ao período após a assinatura do Tratado de Assunção até o final de 2003.

3 Dentre os Países Membros, a Argentina obteve melhores resultados na incorporação de normativas por intermediação parlamentar, com 8,63\% das normas incorporadas; seguido do Paraguai, com 3,10\%; e Uruguai, com 3,05\% (Rivas 2006). 
Internamente aos Congressos Nacionais, as seções da CPC não tinham mecanismos para fazer cumprir suas atribuições de agilização e harmonização das normativas do Mercosul e, portanto, estas deveriam seguir os trâmites ordinários na Câmara dos Deputados e depois seguir os trâmites ordinários no Senado para sua aprovação, o que poderia levar anos para acontecer.

O Protocolo de Ouro Preto (de 1994) promoveu algumas mudanças na CPC: foi reconhecida tanto como órgão da estrutura institucional do Mercosul quanto como uma comissão permanente no Congresso, e assumiu explicitamente a função de agilização das normas emanadas pelos órgãos decisórios do Mercosul nos ordenamentos jurídicos dos países. Em suma, a CPC aceitou como sua função central o papel de "despachante" das decisões tomadas por terceiros no Mercosul.

Mesmo assim, em 1998, o GMC chamou a atenção para os atrasos na incorporação das normas do bloco nos ordenamentos jurídicos nacionais, tanto por processo legislativo quanto por meio administrativo. Em sua Resolução no 22/98, cobrou dos Estados medidas mais eficazes para a aceleração da internalização. A CPC, por sua vez, propôs como solução para essa situação o estabelecimento de uma maior integração com o CMC por meio de um mecanismo mais fluido de comunicação no tocante às questôes legislativas com “(...) a finalidade de garantir uma participação efetiva dos Parlamentos no processo de integração regional” (CPC 1998).

Após o Protocolo de Ouro Preto houve continuidade na forma de atuação da $\mathrm{CPC}$, especialmente quanto à sua capacidade de influência no processo decisório da integração porque ainda produzia recomendações sem valor legal ou obrigatoriedade de consideração (Drummond 2010). Além disso, o reconhecimento formal como comissão permanente do Congresso não se traduziu em termos práticos, como demonstra a fala da Senadora Ideli Salvatti (PT-SC) sobre as negociações para a criação do Parlasul:

Como Membro da Comissão Mista do Mercosul, causou-me bastante estranheza o fato de não termos tido conhecimento prévio da viagem. Entendo ser bastante estranha a ausência de representação do Senado da República em uma atividade desse porte, de tratativa do Parlamento do Mercosul. Portanto, gostaria de saber se o Senado foi questionado ou avisado de que a viagem iria ocorrer, para que nos associássemos, tendo em vista que a iniciativa é altamente meritória. (Salvatti 2003).

A questão do reconhecimento e da incorporação da CPC na institucionalidade do Mercosul é um ponto fundamental para entender a atuação parlamentar porque, embora tenha alterado seu status, não significou uma modificação no seu comportamento, no seu poder decisório e nem mesmo na sua importância. O Poder Legislativo na integração permaneceu como uma instância subordinada e consultiva do Executivo. 
Minha explicação para essa participação parlamentar limitada e reativa no âmbito regional se fundamenta basicamente no problema de sobrevivência política. Os parlamentares constataram que a atuação no Mercosul não se traduzia em dividendos políticos, à exceção daqueles cujas bases eleitorais estavam intensamente envolvidas com a integração.

O Mercosul não era um tema central na agenda política interna dos países e nem mesmo do cotidiano dos Legislativos. O desinteresse pela política externa do país por parte da maioria da população é um fato e este apenas se torna um tema de debate público nos momentos de conflito e tensão. Normalmente, as reuniōes de Cúpula do Mercosul são tratadas pelos meios de comunicação como encontros vazios e suas resoluções são vistas com ceticismo, questionando-se a contribuição desse processo para o bem-estar das sociedades.

Essa não é uma visão isolada, embora seja minoritária, e reflete o desconhecimento em torno dos benefícios da integração para as naçôes participantes. Mais do que isso, há um desatrelamento entre as negociações no âmbito do bloco e o processo político interno. De forma bastante simplista, seria como pensar que as decisões tomadas no Mercosul não possuem relação com as estratégias adotadas pelos governos para impulsionar o desenvolvimento. Portanto, existiriam duas agendas políticas: a do chamado interesse nacional estritamente doméstica, e a externa, que buscaria a cooperação com os demais países, e nem sempre atenta aos interesses da nação.

Os parlamentares são políticos que se mantêm dentro desse sistema somente quando eleitos e, para tal, devem atender aos interesses centrais da nação que, no imaginário popular, não têm qualquer vinculação com o Mercosul, que, por sua vez, aparece como não tendo nenhuma relação com as questôes centrais que estimulam o voto nas populações (segurança, saúde, emprego e educação). Além disso, como a integração não é um tema importante para a opinião pública em geral, a atuação nele não se traduz em visibilidade política e nem em mais votos.

Acredito que enquanto houve forte instabilidade política e econômica nos países do bloco havia pouca possibilidade de pensar numa atuação parlamentar mais efetiva porque isto representaria uma potencial perda eleitoral. Essa situação se modificou a partir da nova conjuntura inaugurada no início do século 21 , quando houve uma reorientação na agenda governamental com a vitória de candidatos presidenciais de esquerda que defendiam uma revisão das políticas de cunho neoliberal e propunham uma nova lógica integracionista, pautada na ideia de uma "irmandade de povos" e de um destino comum. A nova perspectiva implementada pelos governos do Cone Sul traduziu-se numa proposta de aprofundamento da integração que se concretizou especialmente em dois sentidos: alteração institucional e ampliação dos participantes.

Os novos governos representavam também a consolidação do processo democrático desses países e a ascensão de grupos políticos defensores de um outro modelo de integração, que vai além dos aspectos comerciais e, portanto, defendiam 
a ampliação da institucionalidade do Mercosul. A proposta não se restringia apenas a criar esferas de participação consultivas, mas visava a incorporar aos poucos esses atores no próprio processo decisório e tornar a integração um tema da agenda nacional.

Para os parlamentares do Mercosul, essa nova perspectiva concretizou-se na proposta de criação de um parlamento regional com atribuições mais amplas do que as desempenhadas pela CPC e com seus membros eleitos diretamente. Abriase a possibilidade de uma redefinição de seu papel no âmbito da integração que estaria mais próxima das funções tradicionais de um legislativo: representação, legislação e fiscalização (especialmente das ações do Executivo).

\section{A herança do Parlasul}

Caetano e Perina explicam que as funções legislativas tradicionais no processo de integração ganham uma conotação específica, apropriada às necessidades da cooperação, para a qual legislação, representação e fiscalização significariam respectivamente internacionalização das normas e acordos do processo integracionista, novas formas de representação por meio de articulação interparlamentar e capacidade de accountability sobre as açôes e decisões dos representantes governamentais (2003, 8-9).

Ainda que essas funções não apareçam de forma explícita nos documentos que deram origem ao Parlamento do Mercosul, a ideia de estabelecer uma instância parlamentar pressupõe que de alguma forma essas atribuições seriam incorporadas na nova institucionalidade. No entanto, o aspecto enfatizado na terceira parte denominada "Mercosul Institucional" - do Programa de Trabalho 2004-2006 apresentado pelo CMC, em sua Decisão no 26/03, era a preocupação com o fortalecimento democrático do bloco que seria alcançado com o aprimoramento nas instituições do Legislativo e do Judiciário na integração (referindo-se ao Parlasul e ao Tribunal Permanente de Revisão do Mercosul, respectivamente).

O Protocolo Constitutivo define no artigo $4^{\circ}$ que as atribuições básicas do Parlasul são fortalecer a cooperação entre os Parlamentos, elaborando inclusive estudos e anteprojetos de normas nacionais, orientados à harmonização das legislações nacionais; agilizar a incorporação das normas do Mercosul nos ordenamentos jurídicos de cada país; contribuir para a representação dos interesses dos cidadãos; e fortalecer o compromisso democrático do Mercosul. Nesse último caso, reforçaria os princípios da democracia representativa definidos nas Constituições nacionais e no Protocolo de Ushuaia - de 24 de julho de 1998 -, embora os parlamentares tenham evitado, até o momento, discutir no âmbito do Parlasul a situação da Venezuela.

O estudo e a elaboração da proposta para a criação do Parlasul foi coordenado pela CPC que tinha até 31de dezembro de 2006 para a sua implantação. Além 
das dificuldades normais para o estabelecimento de uma nova instituição, a Comissão lidou com questões ainda mais básicas, pois não havia consenso entre os parlamentares sobre sua utilidade e necessidade, ou mesmo em relação ao seu papel e se o modelo europeu seria válido para ser seguido (Almeida 1998).

Os Congressos também questionavam a criação de um Parlamento do Mercosul, principalmente por causa das dúvidas sobre quais seriam suas atribuições e como seria a sua relação com os parlamentos nacionais. Nesse último ponto o problema era bem especifico: um parlamento regional seria subordinado ou não aos Congressos?

O Parlamento no Mercosul foi criado sem que esses questionamentos fossem respondidos ou superados. A integração não apresentou uma mudança na sua lógica institucional, mantendo-se o processo decisório centralizado nos Executivos nacionais e estritamente intergovernamental. Além disso, as relações entre os Congressos Nacionais continuam frágeis e houve pouca incorporação da temática regional na agenda dos mesmos, principalmente no Brasil.

Mas a CPC precisava cumprir os prazos e não podia perder a oportunidade que se lhe apresentava de ampliar a participação e importância parlamentar no bloco, o que motivou seus membros a dar continuidade ao projeto de implantação do Parlasul, apesar das dificuldades e incertezas. A estratégia adotada foi de implementar a nova institucionalidade de maneira progressiva, dando tempo para incorporar as novas atribuições e levar adiante as negociações em torno das questôes mais cruciais - especificamente duas: eleições diretas e proporcionalidade.

O novo parlamento regional é uma versão ampliada da CPC, mas com uma proposta de se tornar uma instituição central no âmbito da integração em médio prazo, como aponta o Protocolo Constitutivo do Parlasul, que estabelece duas etapas de transição para a sua implantação plena: de 31 de dezembro de 2006 a 31 de dezembro de 2010 e de $1^{\circ}$ de janeiro de 2011 a 31 de dezembro de 2014.

Na primeira etapa, 18 parlamentares ${ }^{4}$ titulares comporiam o Parlasul. Estes ainda seriam designados por seus respectivos Parlamentos Nacionais; porém, ao longo desse período, os Congressos estabeleceriam as regras para a realização de eleiçôes diretas em cada país. Durante a segunda etapa, seria implementada a nova proporcionalidade (definindo uma nova regra para o número de representantes) e os parlamentares seriam eleitos diretamente pelos cidadãos. Esse seria um período de ajustes para essa nova institucionalidade.

A ideia era usar todo esse período de transição para concluir as negociações mais difíceis e avançar na construção das normas e regras que balizariam a atuação parlamentar nessa nova fase. Talvez por isso o Parlasul ficou ainda muito atrelado à herança da CPC, colocando-se como atribuição central a função de agilização da normativa do Mercosul no âmbito nacional, estabelecendo um mecanismo

4 Nove deputados federais e nove senadores. 
institucional para regulamentar o aspecto consultivo da instância parlamentar do bloco com a regulamentação do acordo interinstitucional ${ }^{5}$, legado da CPC.

Outra função herdada das atribuições da $\mathrm{CPC}$ - e finalmente regulamentada - é a de harmonização das legislaçôes internas nos Estados, tendo extrema importância para o fortalecimento do bloco, pois estabelece a convergência legislativa (Lospennato 2006). O trabalho da CPC foi de escassos resultados nesse aspecto, devido em parte à falta de mobilização dos parlamentares que a integravam e à sua falta de legitimidade nos Parlamentos Nacionais.

Vista de outro ângulo, a transição da CPC para o Parlasul, apesar da relativa continuidade, apresentou alguns avanços como a forma de organização, o mecanismo decisório e a produção documental. A CPC se organizava em Subcomissões sem caráter estatutário permanente, funcionando como instrumentos ad hoc, o que impedia a especialização dos parlamentares ou uma formação progressiva das suas aptidóes. O Parlasul estabeleceu em seu Regimento Interno dez comissões permanentes e permite em seu estatuto a criação de comissões especiais e comissões temporárias para a análise de algum tema pertinente.

As comissões e subcomissões são instâncias centrais na atividade parlamentar porque é no seu interior que se realiza a instrumentalização dos estudos sobre temas específicos, os diálogos com a sociedade civil e a produção documental. No caso específico desta última, a CPC se manifestava aos outros órgãos do Mercosul por meio de recomendaçôes e às instâncias da sociedade por meio de declaraçôes.

A produção das recomendações acompanhava os rumos do processo de integração sugerindo aos órgãos decisores do bloco ações específicas ou gerais que se julgavam pertinentes. No entanto, essas se apresentaram sempre com um caráter genérico e amplo. Dois motivos podem ser atribuídos a esse fato: não obrigatoriedade de consideração pelos órgãos decisores, e o próprio modo do processo decisório interno da CPC, por consenso. No primeiro caso, verifica-se uma desmobilização dos parlamentares para produzir estudos aprofundados já que não havia um mecanismo institucional que obrigasse a consideração dessa proposição; no segundo caso, a deliberação por consenso reduzia a possibilidade de discutir problemas específicos e/ou polêmicos, ou seja, a forma definida para o processo decisório desarticulava a capacidade de deliberação e tirava a função primordial do parlamentar que é o voto.

A produção documental que o Protocolo Constitutivo do Parlamento do Mercosul (PCPM) prevê é mais abrangente, ao estabelecer um caráter propositivo por meio da elaboração de projetos de normas e anteprojeto de normas que serão encaminhados ao CMC, ao mesmo tempo em que mantém a possibilidade de

5 A CPC e o CMC assinaram um acordo interinstitucional em outubro de 2003, pelo qual o CMC assumiu o compromisso de consultar previamente a CPC nas negociações que demandassem aprovação legislativa, e em contrapartida a Comissão comprometeu-se em agilizar a internalização das normas do Mercosul nos Congressos Nacionais por meio de suas Seçôes Nacionais. “(...) Lamentablemente este acuerdo interinstitucional nunca se reglamenta, y como en tantos otros casos, lo que parecía un salto cualitativo queda a mitad de camino, y nunca se vuelve efectivo" (Lospennato 2006, 20). 
elaboração de Recomendações e Declarações a outros órgãos ou instâncias da sociedade.

Apesar da debilidade em influir nas decisóes, a CPC procurou exercer a legitimação do processo de integração elaborando recomendações aos órgãos decisores sobre os rumos da integração, ainda que sem valor legal, obrigatoriedade e sofrendo com o "desconhecimento" dos Congressos Nacionais sobre essa instituição.

Outro aspecto importante do PCPM refere-se à representação dos interesses dos cidadãos, ao estabelecer reuniões semestrais com o Fórum Consultivo Econômico-Social (FCES) ${ }^{6}$ para intercambiar informações sobre o desenvolvimento do Mercosul, e prever a organização de audiências públicas com a sociedade civil e os setores produtivos, e seminários com especialistas.

Esses mecanismos de diálogo com a sociedade já existiam e eram aplicados durante o período da CPC. A questão era a pouca eficácia deles no tratamento dos problemas e assuntos abordados. Normalmente as discussões não se traduziam em alguma ação prática, mesmo porque a própria Comissão não tinha capacidade de influir decisivamente nas negociações do bloco. Em outras palavras, se algum setor ou grupo tivesse algum interesse específico em relação ao Mercosul, o seu interlocutor preferencial não era a Seção Nacional da CPC, mas os representantes do Poder Executivo que eram negociadores de fato e poderiam decidir sobre a questão.

Essa situação não se alterou, aparentemente, com a institucionalização do Parlamento. Qual a capacidade do Parlasul de influir nas negociaçôes regionais de maneira propositiva, representando os interesses da sociedade civil? Permanece a mesma de antes: pode propor projetos de normas do Mercosul que serão considerados pelo CMC, que é a instância que decidirá sobre a sua incorporação ou não, e como o assunto está sendo tratado. De fato, uma vez encaminhada a proposta, o CMC se obriga a apenas informar semestralmente ao Parlasul como esta está sendo tratada.

O caráter propositivo é um avanço se considerado do ponto de vista de que supera o legado da CPC, meramente consultivo. Porém, de uma perspectiva das atribuições tradicionais do Poder Legislativo há claramente um desequilíbrio entre os Poderes, pois o CMC - órgão representante do Poder Executivo e de estrutura intergovernamental - permanece sendo a instância com poder decisório máximo na integração. Ou seja, após os parlamentares do Mercosul elaborarem uma normativa, que deve ser discutida e votada, esta ainda deve passar pela avaliação do CMC, que, em consenso entre os Estados Partes, deve decidir pela aprovação ou veto dessa norma. Em última análise, os parlamentares não têm capacidade legislativa na integração regional.

Das atribuições tradicionais de um Parlamento - legislar, representação e controle -, as duas primeiras apresentam dificuldade na sua plena execução, pois a representação fica prejudicada pela limitação em transformar os interesses em decisões concretas, sem dizer a total ausência de poder decisório. Assim sendo, o

6 O FCES é um órgão representante da sociedade civil organizada e do empresariado. 
Parlasul representaria um avanço real imediato em relação à CPC, se ampliasse suas atribuiçōes e poder.

A atribuição de fiscalização do processo de integração é uma das principais funções do Parlamento Europeu, mas no caso do Mercosul ela é limitada porque o Parlasul não tem controle sobre o orçamento do bloco, restringindo-se ao acompanhamento do programa de trabalho proposto pelo Presidente pro tempore do CMC ao início de cada mandato. ${ }^{7}$

Até o momento, esse tipo de controle parlamentar mostrou-se ineficiente, em virtude da falta de informações e diálogo com os negociadores do bloco, assim como pelas próprias deficiências institucionais. A alteração estabelecida de encaminhar as normas elaboradas pelos órgãos decisores para apreciação dos parlamentares do Parlasul ainda no processo de negociação poderá significar um fortalecimento da função de controle, mas até o momento não se verificou essa mudança e os parlamentares apenas recebem a informação do plano de trabalho proposto pela presidência pro tempore e, no final do mandato, um informe sobre o que efetivamente foi realizado.

Essa continuidade em relação à CPC é natural porque a institucionalização do Parlasul se fundamenta nessa instância de participação anterior, herdando em boa medida comportamentos e regras de sua antecessora. A crítica que se faz é sua dificuldade em ir além e assumir um papel mais relevante na integração, mas isso implica discutir certos princípios do próprio processo que provocam fortes reaçōes tanto para os negociadores como para os sistemas políticos nacionais.

\section{Consequências inesperadas do Parlasul}

Dr. Rosinha (PT-PR) é um entusiasta do Parlasul e foi um de seus proponentes, defendendo a sua criação como um instrumento para dar maior institucionalidade e segurança jurídica ao Mercosul e superar o deficit de participação e cidadania presente no bloco porque sua existência promoveria um aprofundamento no processo, trazendo o debate político para o seu cotidiano e estimulando a formação de uma identidade política e uma cidadania regional (Dr. Rosinha 2009).

Essa percepção foi compartilhada por aqueles que apoiaram essa proposta $\mathrm{e}$ que, em boa medida, também defendem a ideia de aprofundamento da integração. Grupo este fortalecido com a ascensão dos governos de esquerda nos países do Cone Sul no início dos anos 2000 e sensíveis à concepção de que a cooperação entre essas nações era uma questão de identidade regional que ultrapassava a preocupação com os aspectos comerciais.

A criação de um parlamento emprestava ao discurso de relançamento do Mercosul uma força simbólica importante ao trazer para o âmbito regional a figura de uma estrutura representativa dos sistemas políticos democráticos, simbolizando

7 A presidência pro tempore do CMC é rotativa e dura seis meses. 
a incorporação da sociedade por meio de seus representantes e a vigência de uma nova agenda de negociação.

Porém, a realidade mostrou que esse passo em direção ao Parlasul teria implicaçōes mais profundas do que o esperado. A nova institucionalidade representava a necessidade de estabelecer novas regras e a participação de novos atores no processo decisório, implicando novos comportamentos e princípios no Mercosul.

A eleição direta dos seus membros, embora seja tratada por muitos como um mero simbolismo, traz em si uma mudança estrutural na integração ao representar um primeiro indício de supranacionalidade: ao estabelecer que os membros do parlamento não serão indicados por nenhuma instância estatal, abre-se o precedente da institucionalização legítima de uma esfera que foge à lógica intergovernamental.

Aliada a essa questão está a proposta da representação proporcional não pelo número de países integrantes do bloco, mas pelo tamanho populacional de cada um. Novamente, a perspectiva intergovernamental é colocada em xeque porque o número de representantes não se refere mais aos governos, mas à sociedade.

Esses dois aspectos são as mudanças fundamentais do Parlasul em relação à CPC e são os pilares sobre os quais se estrutura a proposta de longo prazo dessa nova instituição. Apesar de sua centralidade e aceitação desde o início, o fato é que suas consequências geram inquietações e resistências, o que dificultou a sua negociação.

Como apontei anteriormente, o PCPM estabeleceu que até o final da primeira etapa de transição todos os membros do Parlasul teriam sido eleitos diretamente, respeitando os números estabelecidos pelo acordo de proporcionalidade. Não foi o que aconteceu. $\mathrm{O}$ único país que cumpriu o estabelecido foi o Paraguai, tendo sido fortemente criticado como precipitado pelos demais.

O problema para o cumprimento do disposto no PCPM deveu-se à dificuldade na negociação do acordo sobre a proporcionalidade e sobre as regras para a eleição direta dos parlamentares. De acordo com depoimentos parlamentares (Dr. Rosinha 2009; Canese 2009), além dos entraves intrínsecos à discussão em torno dos tamanhos das futuras bancadas, os governos trouxeram para a mesa de negociação questôes vinculadas com interesses nacionais.

A proposta estabelecida no início do período de transição foi aprovada somente na última reunião de cúpula do Mercosul (dezembro de 2010) em Foz de Iguaçu, quando finalmente os quatro governos aceitaram os termos do acordo que estabeleceu como novo prazo 31 de dezembro de 2014 para que todos os membros do Parlasul sejam eleitos diretamente. Enquanto não houver eleições diretas, os países continuarão indicando seus representantes que necessariamente devem possuir mandatos eleitos por voto direto - ou seja, permanece a atual regra da indicação de parlamentares do Congresso Nacional -, mas alterando a atual proporção.

$\mathrm{O}$ acordo sobre proporcionalidade estabelece que somente Uruguai ${ }^{8}$ e Paraguai manterão os atuais 18 membros; Argentina terá 26 parlamentares até

8 Uruguai é o único país que ainda não estabeleceu um prazo para a realização da eleição direta de seus representantes para o Parlasul. 
realizar a eleição direta em 2011, após a qual sua bancada subirá para 43, enquanto o Brasil ficará com 37 até o pleito previsto para 2012 e 75 depois dessa data.

O estabelecimento desse acordo coloca no horizonte um conjunto de desafios e mudanças significativos. Em primeiro lugar, está o problema sobre a determinação dos critérios para a eleição de um representante para o Parlasul. Esse ponto levanta uma questão central para o conjunto dos atores políticos, que é a desinformação sobre a integração no Mercosul, o que muitas vezes se traduz em desinteresse pelo processo ou até mesmo oposição.

A sociedade e os partidos políticos não debatem sobre o Mercosul, a não ser quando diretamente afetados por ele, como ocorre nos estados fronteiriços no sul do Brasil ou norte da Argentina. A criação do Parlasul poderia ser um avanço nesse sentido porque estimularia a mobilização e a vontade de influenciar o processo, incorporando aos poucos o bloco no cotidiano da sociedade, aumentando a sua importância na agenda política nacional e na dos parlamentares. Para os legisladores, seria uma ampliação da sua esfera de atuação e da possibilidade de consolidar novos núcleos de apoio político fora de seus tradicionais redutos eleitorais. No entanto, o estabelecimento de eleições diretas nesse momento pode não ter esse efeito esperado.

Até agora não se percebe nas nações do Cone Sul mobilização parlamentar mais significativa, com a pretensão de estimular o debate sobre o Mercosul na sociedade. Uma explicação é a falta de vontade política decorrente da ausência de uma percepção clara sobre os benefícios resultantes de uma medida como essa. Os parlamentares, em geral, não têm clareza sobre quais seriam os custos e as vantagens de se candidatarem para o Parlasul.

A eleição direta para um parlamento regional pressupõe um amadurecimento do debate sobre a integração na esfera política, no sentido de estabelecer uma função real para esses parlamentares que vá para além das atribuiçôes de despachantes das normativas do Mercosul (decididas por terceiros), de interlocutor da sociedade sem poder decisório ou de um controle precário sobre a execução dos planos de trabalho do CMC.

A fala do deputado Germano Bonow (DEM-RS) expressa essa percepção ao afirmar que os partidos não estão dando a devida importância ao Parlasul e ao próprio Mercosul. "A maioria dos deputados não sabe o que é o Mercosul e se os deputados não sabem, o povo sabe menos ainda (...).” (Bonow 2009, citado por Icassatti 2009).

Essa fala também supõe uma discussão profunda sobre o projeto de integração que se pretende implementar em médio e longo prazo, e na incorporação desse modelo no projeto nacional e nas estratégias de desenvolvimento desses países, já não mais pensadas de forma isolada, mas inseridas numa lógica regional. Tudo isso implica a existência de um debate intenso nas instâncias políticas nacionais sobre o Mercosul, o que não se verifica.

Essa fragilidade é reconhecida pelos parlamentares e por representantes da sociedade civil que participam de forma mais ativa no bloco. Adicione-se a 
essa preocupação o fato de que as eleições diretas para o Parlasul serão realizadas conjuntamente com votações para representantes de instâncias nacionais. Nesse caso, a experiência paraguaia demonstrou que sem um trabalho de divulgação prévio, o acoplamento dos dois pleitos desvia a atenção da temática regional para as questōes de interesse imediato da população.

O deputado Canese (2009) e o ex-senador Castaing (2010) relataram que durante as eleições paraguaias a questão da integração não foi debatida e que a população em geral não sabia por que estava votando para o Parlasul, quem eram os candidatos para representá-los nessa instituição e muito menos qual seria a função e papel destes no processo. Tal desconhecimento é visto com apreensão pelos parlamentares porque poderia se traduzir em descrédito, refletindo no parlamento regional a imagem desgastada que o âmbito legislativo enfrenta hoje nesses países.

Superar esse desconhecimento é entendido como uma tarefa central para fortalecer essa instituição e consolidar as bases para impulsionar a chamada democratização da integração. Algumas propostas estão sendo encaminhadas nesse sentido. Segundo o deputado Dr. Rosinha - redator da lei eleitoral brasileira referente às regras para a realização das eleições no Brasil para o Parlasul -, o projeto que tramita hoje no Congresso Nacional prevê que 180 dias antes do pleito haveria inserções e campanhas nos meios de comunicação explicando o Mercosul e o Parlamento.

Mas a questão central vai além da divulgação de informações. As eleições pressupóem uma mudança de comportamento e de interesses nos atores. Os candidatos ao Parlasul seriam políticos dispostos a sair da rotina imposta pela agenda nacional e se voltar para as temáticas regionais, que não chamam a atenção da opinião pública.

A aposta desses atores é que a regra da eleição direta estimule esse novo comportamento, porque os parlamentares deixariam de dividir suas atenções entre a agenda da integração e as demandas nacionais, voltando-se exclusivamente para refletir sobre o projeto regional que pretendem defender. A dedicação em tempo integral também facilitaria a aproximação entre os grupos políticos, criando um novo espaço de articulação desvinculado do debate nacional ou filiaçōes partidárias.

É possível afirmar que a efetiva implantação da nova regra e o amadurecimento da institucionalização do Parlasul, tal como foi planejado, seriam capazes de democratizar o processo de integração e de aproximar essa temática do cotidiano das sociedades envolvidas, mas também despertarão um forte questionamento do atual modelo de integração no tocante à sua lógica institucional.

À medida que os integrantes do Parlasul tiverem uma atuação mais efetiva e maior envolvimento na integração, as reivindicaçõos por maior poder decisório tendem a se intensificar. A atual situação de total subordinação ao CMC seria questionada sob a justificativa inclusive de que a legitimidade outorgada pelas urnas demandaria desses parlamentares um novo papel ou status no Mercosul. 
Considerando a postura apresentada pelos governos nos últimos 20 anos de integração, é possível prever que essa pressão parlamentar encontraria forte resistência por parte dos grupos governamentais que hoje centralizam o poder decisório no Mercosul - especialmente os ministérios de relações exteriores. A solução desse impasse é uma incógnita, mas teria reflexos interessantes para o processo como um todo.

Se os parlamentares do Parlasul perdessem o embate, isso explicitaria quais são os reais limites do processo de integração e de seu aprofundamento. $\mathrm{O}$ intergovernamentalismo deixaria de ser uma questão de adequabilidade ao estágio da integração - como afirmam seus defensores - para se evidenciar como o centro de sua identidade, não permitindo às suas estruturas institucionais qualquer almejo de mais autonomia.

No caso de uma vitória dos membros do Parlasul, são múltiplas as possibilidades de desdobramento, mas é provável que um novo impasse se imponha não mais com as esferas decisórias do Mercosul, mas com os próprios Congressos nacionais. Um Parlasul com participação efetiva no processo decisório significaria parlamentares com capacidade legislativa, porém as atuais regras pressupōem que as decisóes tomadas no âmbito regional devem ser aprovadas pelos respectivos Parlamentos para entrar em vigor.

Para obter o apoio dos Congressos para a aprovação da institucionalização de um parlamento no Mercosul, os negociadores dessa proposta preocuparamse em não criar atritos desnecessários naquele momento (Dr. Rosinha 2009), deixando claro que não afetariam os âmbitos nacionais, e manteriam em vigor a prática estabelecida ainda pela CPC e prevista no acordo institucional de que os parlamentos nacionais tramitariam no prazo máximo de 180 dias as normas previamente analisadas e aprovadas pelo Parlasul' .

$\mathrm{O}$ acordo institucional pressupõe que as decisões tomadas pelo CMC são analisadas pelos membros do Parlasul (indicados pelos Congressos) e que estes avaliam a sua legalidade perante as normas nacionais vigentes, acelerando os tradicionais procedimentos de análise dessas casas legislativas. Contudo, numa situação em que parlamentares legitimados pelo voto direto como representantes das sociedades no Mercosul decidem e aprovam uma norma regional, qual a necessidade de submeter novamente essa decisão aos Parlamentos nacionais?

Alguns poderiam responder que isso seria necessário para garantir a adequabilidade às constituições vigentes. Minha resposta é que existe hoje a institucionalização de instâncias de consulta recíproca e troca de informações que de acordo com a sua regulamentação cumprem justamente com essa função - são as chamadas unidades de enlace dos respectivos Congressos.

Essas são apenas conjecturas pensadas a partir da ideia de que a implantação das eleições diretas representará uma mudança significativa no comportamento dos

9 As normas que não tenham a aprovação prévia do Parlasul seguem a tramitação normal. Como apontei anteriormente no texto, isso significa que o projeto pode ficar anos tramitando. 
parlamentares do Parlasul. Reconheço que essas novas atitudes serão acompanhadas de resistências, porque é difícil abandonar padrões de ação rotinizados e sedimentados nos atores. Porém, a incorporação de uma nova regra pode gerar consequências muito mais amplas do que as previstas por aqueles que a adotaram.

À medida que se estruturam novas instâncias de participação, seu impacto vai além da mera criação de mecanismos para responder às demandas, gerando mudanças na agenda política que podem fugir ou extrapolar os limites definidos pelo Estado-Nação, tendo a capacidade de levar a um aprofundamento da cooperação.

Esse papel de consolidação do processo não resulta de uma atuação deliberada por parte dos parlamentares no sentido de assumir esse papel, pois esse objetivo não aparece na sua agenda ou nas propostas. Isso ocorreria como resultado do que chamo de consequência inesperada: os parlamentares eleitos pelo voto direto, ao atenderem aos seus interesses próprios, gerariam coletivamente um resultado inesperado que pode alterar os rumos da integração, voltando-a para um processo de aprofundamento que, no caso do Mercosul, não é desejado neste momento pelos governos nacionais.

Paul Pierson (1998) aponta de forma clara como esse mecanismo ocorreu no caso da Europa, onde a evolução das organizações comunitárias e das suas políticas públicas levou ao surgimento de lacunas no controle dos chefes de governo, criando espaços para a participação dos atores não governamentais que influenciam a integração ao mesmo tempo em que limitam a margem de manobra de todos os atores políticos, levando ao que esse autor chama de lock in.

No caso europeu, as instituições regionais receberam autoridade dos governos para executar suas funções, desfrutando de uma autonomia parcial. Com o tempo passaram a utilizar parte dessa autoridade para seus próprios propósitos; dentre eles, aumentar essa autonomia, gerando uma disputa entre os governos nacionais e as organizações comunitárias em torno dessas lacunas de controle dos primeiros sobre as segundas.

A expansão das atividades políticas e das decisões das instâncias comunitárias na integração europeia aumentou o número de atores envolvidos, provocando maior complexidade e, segundo Pierson, uma sobrecarga que facilitou o aparecimento de consequências inesperadas e de falhas no controle dos Estados-membros sobre as instituições do bloco.

Como resultado, uma vez "instituída" a falha de controle, é muito difícil voltar atrás porque enfrenta-se a resistência dos atores organizacionais da comunidade e aparecem obstáculos institucionais para reformas na Comunidade Europeia no sentido de estabelecer retrocessos - que representam custos excessivos para os chefes de governo, que têm como única margem de manobra nesses casos evitar que esses "erros" se repitam nos novos acordos e instituições.

Ainda que a dinâmica europeia do lock in não tenha relação direta com a situação atual do Mercosul, a institucionalização do Parlasul tal como foi 
pensada abre a possibilidade de imprimir esse tipo de lógica do lock in num processo de integração caracterizado pelo seu apego às estruturas institucionais intergovernamentais que, em princípio, seriam barreiras para o desenvolvimento dessas falhas de controle, direcionando o processo para uma tendência de aprofundamento.

Apesar desse controle sobre as instituições e seu processo decisório, não há garantias de que as novas regras definidas para a participação parlamentar não provocarão pressões por mudanças que podem alterar esse cenário e até mesmo a agenda do bloco regional. Isso porque à medida que a integração avança no tempo, ela tende a incorporar novos atores e a lidar com os resultados de suas decisões, com seus efeitos colaterais imprevistos ou não antecipados.

No caso do Mercosul, os governos apoiaram a criação do Parlasul, com integrantes escolhidos por meio de eleições diretas, acreditando que estariam atendendo às demandas por democratização do processo de integração e maior aprofundamento institucional. Ao mesmo tempo, supunham que essas medidas não alterariam o princípio fundamental de todo o processo, a lógica intergovernamental. Não notaram que estavam abrindo a Caixa de Pandora.

\section{Referências bibliográficas}

ALMEIDA, Paulo Roberto de. Mercosul: fundamentos e perspectivas. São Paulo. LTr, 1998.

CAETANO, Gerardo e PERINA, Ruben (eds.). La encrucijada politica del Mercosur. Parlamentos y nueva institucionalidad. Montevidéu: CLAEH e UPD-OEA, 2003.

CANESE, Ricardo (Parlamentar do Mercosul pelo Paraguai). Apresentação no Seminário Internacional Parlamento do Mercosul e sociedade civil: caminhos para uma maior democratização da integração regional. Rio de Janeiro: Instituto Rosa Luxemburgo Stiftung (IRLS) e Instituto Solidariedade, 1 e 2 de setembro de 2009.

CASTAING, Mario Paz. Apresentação no Painel "Parlasur: actor clave en la formación de la identidad regional", no Seminário do FOMERCO Sudamérica, comunidad imaginada. Emancipación e integración. Buenos Aires: 9 de setembro de 2010.

COMISSÃO PARLAMENTAR CONJUNTA/Seção Brasileira. Atas das Reuniōes. 1995-2006. Disponível em: <http://www2.camara.gov.br/comissoes/cpcms/> e <http://www.senado.gov.br/ evmmercosul/homeptg/Abertura.htm>, acesso em 13 de maio de 2008.

COMISSÃO PARLAMENTAR CONJUNTA: Regimento Interno, 1991. Disponível em: $<$ http://www2.mre.gov.br/unir/webunir/bila/esp/mercosul/10regcpc.htm>, acesso em $10 \mathrm{de}$ maio de 2008.

COMISSÃO PARLAMENTAR CONJUNTA: Regimento Interno, 1995. Disponível em: <http://www.senado.gov.br/evmmercosul/M731/..\%5Cpublico\%5Csetores\%5C000\%5C3 9\%5Creunioes\%5C1995\%5C23\%5CV-ActaReunion.doc>, acesso em 12 de maio de 2008.

COMISSÃO PARLAMENTAR CONJUNTA: Regimento Interno, 1997. Disponível em: <http://www2.camara.gov.br/comissoes/cpcms/normativas/rgulamentocpc.html>, acesso em 12 de maio de 2008. 
COMISIÓN PARLAMENTARIA CONJUNTA DEL MERCOSUR Y FUNDACIÓN KONRAD ADENAUER. Hacia el Parlamento del MERCOSUR: una recopilación de documentos. Montevidéu: 2004.

DABÈNE, O. "La reactivación del Mercosur: Ouro Preto II o el tiempo de las reformas políticas" in Oasis, n 10. Bogotá: 2004. (p. 119-27)

DR. ROSINHA (deputado federal do PT). Apresentação no Seminário Internacional Parlamento do Mercosul e sociedade civil: caminhos para uma maior democratização da integração regional. Rio de Janeiro: Instituto Rosa Luxemburgo Stiftung (IRLS) e Instituto Solidariedade, 1 e 2 de setembro de 2009.

DRUMMOND, Maria Cláudia. A Democracia Desconstruída. O déficit democrático nas relaçôes internacionais e os parlamentos da integração. Brasília: Senado Federal, Subsecretaria de Edições Técnicas, 2010.

ICASSATTI, Ricardo. "Normas para eleição ao Parlasul ainda sem consenso" in Agência Senado. Brasília: Portal de Notícias Senado Federal, $1^{\circ}$ de julho de 2009. Texto completo em <http:// www.senado.gov.br/noticias/normas-para-eleicao-ao-parlasul-ainda-sem-consenso.aspx>.

LOSPENNATO, S. "Déficit democrático y evolución institucional del MERCOSUR: hacia el Parlamento Regional” in Revista Mercosur Parlamentario, n. 1. Buenos Aires: maio 2006. (p. 15-23)

MARIANO, K. L. P. Integração regional do Cone Sul: os partidos politicos e as centrais sindicais do Brasil. Tese (Doutorado em Ciências Sociais)- Instituto de Filosofia e Ciências Humanas, Universidade de Campinas. Campinas: 2001.

MARIANO, M. P. e MARIANO, K. L. P. "As teorias de integração regional e os Estados subnacionais" in Revista Impulso, v. 13, n. 31. Piracicaba: Editora UNIMEP, maio/ago. 2002. (p. 47-69)

OLIVEIRA, M. F. de. Mercosul: atores politicos e grupos de interesses brasileiros. São Paulo: EDUNESP, 2003.

PARLAMENTO DO MERCOSUL. Atas das Reuniōes. 2007-2010. Disponível em <http:// www.parlamentodelmercosur.org/index1_portugues.asp\#>, acesso em 20 de junho de 2008.

PARLAMENTO DO MERCOSUL: Regimento Interno, 2007. Disponível em: <http:// www2.camara.gov.br/comissoes/cpcms/parlamento.html/regimento-interno-do-parlamentodo-mercosul-portugues $>$, acesso em 12 de maio de 2008.

PIERSON, Paul. “The Path to European Integration: A Historical-Institutionalist Analysis” in SANDHOLTZ, Wayne e SWEET, Alec Stone (eds.). European Integration and Supranational Governance. New York: Oxford University Press, 1998. (p. 27-58)

PROTOCOLO CONSTITUTIVO DO PARLAMENTO DO MERCOSUL, 2005. Disponível em: <http://www2.camara.gov.br/comissoes/cpcms/parlamento.html/protocolo. html/protocoloparlamentomercosul.html>, acesso em 11 de maio de 2008.

RIVAS, E. "Adopción e internalización de la normativa comunitaria en el seno del MERCOSUR: Un repaso histórico" in Observatorio de la Economía Latinoamericana No 62, junho de 2006. Texto completo em <http://www.eumed.net/cursecon/ecolat/>.

SALVATTI, Ideli. "Pronunciamento" Portal Atividade Legislativa-Senado. Brasília: 22 de julho de 2003. Disponível em: <http://www.senado.gov.br/atividade/Pronunciamento/det Texto. asp?t=338118>, acesso em 13 de maio de 2008. 
VAZQUEZ, M. "La Comisión Parlamentaria Conjunta del Mercosur: reflexiones sobre su trayectoria político-institucional”. Prepared for delivery at the 2001 meeting of the Latin American Studies Association. Washington, D.C. 6-8 de setembro de 2001. Texto completo em <http://lasa.international.pitt.edu/Lasa2001/VazquezMariana.pdf>.

VENTURA, D. e PEROTTI, A.D. El Proceso Legislativo del Mercosur. Montevidéu: Fundación Konrad-Adenauer, 2004.

Recebido em 17 de março de 2011 Aprovado em 25 de maio de 2011

\section{Resumo}

Este artigo analisa a representação parlamentar no Mercosul e as implicações da institucionalização do Parlasul, expondo como este foi pensado e os desdobramentos de sua institucionalização, tendo presente uma preocupação em identificar mudanças ocorridas a partir de sua atuação, e de sua relação com os órgãos decisórios do Mercosul e os Congressos Nacionais.

Palavras-chave: Integração; Mercosul; Parlasul.

\section{Abstract}

This article examines the parliamentary representation in Mercosur and the implications of the institutionalization of Parlasur, exposing how it was meant and the consequences of its institutionalization. Its aim is to identify changes and its relationship with policy-making bodies of Mercosur and National Congresses.

Keywords: Integration; Mercosur; Parlasur. 